\title{
Professional Work, Professional Careers and Legal Education: Educating the Lawyer for 2010
}

Professor Avrom Sherr, Institute of Advanced Legal Studies, University of London, England

\begin{abstract}
This chapter considers how legal education and training should react to change in the legal professions. It refers briefly to existing literature on the character of these changes, and develops information on new forms of legal work. It then goes on to consider a set of developing legal concepts and legal subject areas in order to begin a critical discussion of whether, and how, legal education should reorganise in view of the changes in the profession.
\end{abstract}

Abel has charted transformation in the legal professions of England and Wales as elsewhere. He considers changes in the demographics of the legal profession, in elements of structure and behaviour. Hanlon further investigates the relationship between the profession, the state and the market. They concentrate on the 'external' forces bringing about professional transformation. In this chapter the 'internal' manifestations of contemporary professional change are brought into focus. In an earlier piece this author noted elements of difference in the work and work practices of legal professionals, such that the paradigms of legal work were changing and the typical images of the legal professional, so beloved in the literature, were giving way to new images. Two of these merited direct attention as a means of showing how far the changes had reached. The "superhero/ine" was a character who suddenly entered onto the scene of some disaster or major emotional life change for an individual or a business entity. The superhero "saves" the day, places the damsel in distress back on top of the mountain and leaves the scene to find other disasters to remedy. The superhero knows nothing of the person who is saved before the moment of salvation, or afterwards. The superhero is involved for a short period of time and does not have continuity, background knowledge, deep understanding, commitment or followthrough, but simply crisis intervention. It was suggested that many lawyers were now working in this mode. The day to day life and work of individuals or corporate entities did not involve their lawyers. It was only when some major change or major crisis occurred that the lawyer was brought in.

The results of specialisation in the legal profession, competition and changes in legal aid have led to a form of industrialisation within the legal sector. Legal work is often organised in a more standardised and repetitive fashion. Work is de-skilled and broken up into different activities which can be handled by lower level operatives. Many working within this new system find it easier to begin areas of highly complex work. However, long hours and the repetitive nature of the work have caused many young solicitors stress and worries about whether they have made the right choice of career. Hence the "slave" image.

In "Client Care for Lawyers", the resultant changes in the paradigm of the lawyer client relationship were considered. Instead of one lawyer carrying out all the work on an individual client's matter from first interview to closing the file, the paradigm has now changed. Different lawyers, paralegals and others may deal with the different 
elements of a legal matter and with the client through the course of each case.

Different skills therefore become important, different levels of understanding and assumption and therefore possibly different approaches in education, training and socialisation of neophyte lawyers to these tasks.

In "Little Bo Peep" the state of legal education was reviewed under the circumstances of more choice available to law schools to decide what they would wish to teach. It is there argued that law schools had been able to "hide" behind the dictation of a core by the legal professions, although in fact, the professions allowed far more licence than appeared. Now that there is more choice, where should the law schools turn in order to decide what, and how they should teach? Law schools like "little Bo Peep" seemed to have lost their sheep, unable to find a new basis for what they should teach.

Attention needed to be paid to what was happening in the legal profession as well as the state of knowledge within black letter law, the state of knowledge within sociolegal theory and the state of knowledge across other disciplines. Since law and the work of law was so largely defined by the work of the legal profession it was essential to take into account what was happening there.

In this chapter it is intended to pose questions about the future content, style and objectives of legal education, in order to initiate a discussion. It will, as always, be easier to ask the questions than to answer them. But failing to ask the questions means that answers are even less likely to appear.

This chapter therefore considers how to approach the issue of educating law students, some of whom may be actually going into legal practice, and many more of whom will be wanting to go into legal practice, beyond the turn of the century. Legal practice itself seems to have provided, until now, some guide for what an undergraduate law degree should contain and involve. Will legal practice continue to provide such a plan? Should it? Can we afford to ignore modern or post-modern legal practice?

How should one begin the process of constructing legal education for a globalized, internationally regulated, industrialised, "deprofessionalised" legal profession with its resultant effects on legal careers, legal concepts and legal subject classifications? In order to begin a consideration of these questions some new forms of legal work, new legal concepts and legal subject classifications are considered.

\section{The Paradigms of Legal Work}

Major changes which have occurred and continue in the management and work of the legal professions were characterised previously, as mentioned above, in "Of

Superheroes and Slaves: Changing Images of the Legal Professional". That paper noted, in particular, how the contact between client and solicitors was changing and how the performance and the management of legal work within the law firms were becoming industrialised.

The effect of these changes was that in many cases clients were unlikely to know their lawyers personally, or to have any longer relationship with them than was essential for the case in hand. Lawyers, even those in small high street communities, could not behave like a general practice doctor with long term information about the client and 
the client's family to back up decisions made and follow through with any necessary care or treatment. Instead, the lawyer would be involved in crisis intervention without thinking further of the person saved or the situation remedied.

Further, even during the currency of the contact between lawyer and client, the likelihood is that a set of different individuals within the solicitor's firm would handle different elements of the case and at different times, different people would make contact with the client.

This manifestly changes the paradigm of legal work. The traditional paradigm brought together a solicitor for each client. That solicitor, broadly, dealt with the client and the client's work from the beginning to the end of a matter, sometimes bringing in counsel or more junior lawyers to assist, but rarely. The interface was always between the individual solicitor who begun the matter and the client. That model has not been true for larger firms for many years, but the paradigm has still had considerable force in legal education. All teaching at the undergraduate and at the vocational level still exists broadly around this paradigm and this construction of the lawyer-client relationship and of the nature of legal work.

If the current, not to say, future of legal professional relationships and work will be different then legal education must take this into account - not simply in order to mimic the profession, but in order to prepare lawyers for professional work and in order to understand what the "work of the law" is in its current context. There do not appear to be any current movements within legal education which might accommodate such new paradigms of legal work, or changes in legal concepts and legal subject classifications.

\section{Graduateness}

Work initially on "graduateness" by Professor John Bell and others recently considers notions of what it means, or should mean, to complete any degree level programme of study. Consideration of such issues across the range of different subjects and disciplines stimulates a more general view of the skills which need to be taught in order to prepare graduates for life beyond university, the world of work and their own self development. These core "transferable skills", produced, as they have been, in the context of present day employment needs, are a useful guideline and comparison with the traditional and current practices of the law degree. Further, Professor Bell's continuing work within the "law benchmarking group" for the purposes of the piloting review system set up by the Quality Assurance Agency in Higher Education, extends the general approach of graduateness to the specific area of the law degree. Whilst attempting to maintain and encourage the range of types of law degree the benchmarking standards set in place a view of current "graduateness" in law.

Although no specific attempt has been made to take into account the changing nature of legal professional work in the production of the law benchmarking exercise, the exposure of drafts to the legal professions and the knowledge of those involved in the exercise of the current nature of legal work, seems to have led to a vision of a law degree which may be closer to the current conditions of legal work. Perhaps this means that it is only necessary to provide the occasion for considering change, together with the incentives which the Quality Assurance Agency in Higher 
Education provides (the possibility of a bad review on teaching standards), in order to encourage the changes which are required. Despite some bad press for "benchmarking", some useful modernisation may occur as a result.

\section{Legal Careers}

If legal education needs to think quite differently about the nature of legal careers then it would be sensible to think through what types of legal career, different from our traditional perspectives, can already be seen to be evolving in law firms. Not only are lawyers specialising within particular subject areas or sub-subject areas, but they are also beginning to specialise, at different points in their careers, in different elements of the work process involved in those subject areas. The needs of the workplace are evolving and becoming more defined. Some of these "roles" or "jobs" are stepping stones in a career progression. But, some have begun to solidify into a clearer stratification such that the role, task or job itself becomes a career or "work type", rather than a step along the way.

The nature of jobs and occupations is changing both inside and outside of law, and it is clear that fewer lawyers in the future are likely to have the same certainty of job tenure as in the past. There is already much more movement between firms at both the assistant solicitor level, and also at the partner level, than there has been in the past. But the division of labour enumerated below is a further distinction related to the "industrialisation" of the legal enterprise, forced by costs and some competition and enabled by the large numbers of potential entrants to the legal profession.

A small selection among the occupations observed currently to be evolving are picked out below, as a means of exemplification rather than comprehensive specification.

\section{Draftsperson}

Both a role as stepping stone and an end point, this particular function is one of the more obvious elements of traditional legal work, now taken singularly, rather than as part of a whole case or a repertoire of tasks. The drafting of precedents within a firm, and the upkeep of such precedents is at the heart of industrialisation of the legal process, especially in relation to transactions, but also in relation to repeat litigation. This cannot ultimately be a very junior role. It clearly needs experience of matters as well as the ability to carry out legal research and the work of drafting itself.

In some firms this role appears to be given to an assistant solicitor at "mid-range" between qualification and partnership where they may be taken out of their fee earning position and placed in a separate section devoted to a set of precedent creation and maintenance projects. In other firms, a more senior lawyer, sometimes a partner or ex partner now a consultant to the firm, may undertake this role. At whatever level of experience, the role definition is clear and status will largely depend upon contextual factors such as level, experience and responsibility.

Since this "job", by comparison with other elements of legal work, receives some attention in undergraduate and postgraduate legal education, and especially during the training contract, it may not be seen to require major changes in legal education. But, the definition of this new role provides more clarity than before of its importance as a 
central function for both the solicitors' profession and also for barristers. Its recognition will encourage more concentration on the more technical and more formal side of drafting, than on the more general skills of clarity of expression, rational thought and presentation taught within legal education generally.

\section{Information Officer}

This is already a well-established role within larger law firms often referred to as 'professional support lawyer'. It can sometimes include some of the drafting mentioned above. It more usually includes a general research (and sometimes educational) role in relation to the work of a specific department or subject area. The level and status of this role is already beginning to be well defined. It is often taken up by "mid-range" assistants (two to five years qualified) who do not want the extended hours of service which normal fee earning activity necessitates. Typically, therefore this role is currently often undertaken by qualified solicitors who have trained in a similar firm and who may have carried out two years of fee earning work before deciding to cut down on their hours and commitment; in other words to come off of the fee-earning, partner-track. It is a convenient role for those who prefer either a parttime job or a nine-to-five job. It may also enable parents who wish to continue their careers to enjoy a quieter period of work before returning to the full fray.

The work that information officers do involves a particular need to keep up to date with changes in law and procedure. It also involves the preparation of practice material of a precedential nature, the preparation of industrialised systems for handling multiple similar cases, the preparation of material for practice development purposes, such as updating material organised for clients and some material for the training of lawyers in their departments.

None of these tasks are completely different from the work of fee-earning lawyers. But they deal rather more in overview and in mass distribution than a lawyer centred on the needs of a particular client. The fundamental elements are similar but the approach is really quite different. Their work is carried out more from the viewpoint that legal educators and textbook writers might have which is normally a set of roles taken up, and a viewpoint gained, by considerable experience in further education and writing. There appear to be elements of both viewpoint, skills and approach which are not currently covered in legal education.

\section{Specialist Technician}

Most fee-earning solicitor practitioners do not now conform to the general practice model and most call themselves "specialists". They need, and in some way have to gain, a high level of expertise in their particular areas of practice. Usually, this now occurs through undertaking a training contract in a firm specialising in the specialism concerned, followed by a period of narrowing down in specialism within that firm, or a similar firm - in other words learning by experience, in situ.

Is this the best way to teach the specialist technicians of the future? Have they been taught this way up until now simply because there has been no other way to educate them? Since the bulk of practitioners will probably work in this mode well into the next century, we should be considering more carefully how to educate our specialist 
technicians properly. Will they need the across-the-board general information which currently constitutes the core of knowledge past down to undergraduates and then at the vocational LPC? They might be better served by more specific, or more general forms of undergraduate, vocational and experiential training.

We cannot continue to pretend that we are still educating general practitioners when they do not exist. Nor can we educate in the same way as we have previously, simply because we have not given sufficient thought to what specialists might need.

\section{Advocate}

There have always been advocates. But, until now, in England and Wales this career has been one solely for barristers who have been a referral profession at one step away from clients and at arm's length from their needs.

The new career of solicitor advocate for solicitors arising out of the Courts and Legal Services Act, 1990 is quite different. Its intention is to allow for somebody to interview a client, work on their case and then subsequently carry out the advocacy for them in court. If this is economically viable (and there are some serious doubts that it may not be), this new legal career will need new forms of approach. A barrister always had the possibility of being more objective than a solicitor who needed to deal with the day to day problems of clients. The barrister could always look at the case "de novo" and could behave rather like the court, without the burden of the client's feelings. This may well have been a useful position for the court advocate.

But how will the new solicitor advocates be able to manage this? Thought needs to be given to the elision of these two roles. How can somebody be the close contact and "friend" at the same time as being an objective, court-serving advocate? Clearly, such issues will need a development of theory, a development of legal ethics, and also a level of development of skill. All of this needs to come from an understanding of the education and training issues involved.

\section{Manager}

As law firms have grown, management has become a major issue. Management of the work, management of staff, management of clients, management of finance, management of risk, marketing the practice, lobbying civil servants and politicians etc. This entire area is completely untaught both at undergraduate and vocational level, yet it is exactly these issues which cause problems of negligence and misconduct; and it is these issues which cause law firms to fail.

Should we not be considering at a more formal level how to educate our practitioners of the future in the basics of management? Leaving it up to compulsory professional development courses may provide the appropriate timing for immediate need, but it is unlikely to provide the firm foundation which is essential for good management techniques. If the practice of law depends on understanding such issues, should we not bite the bullet and teach these issues at the vocational level? If existing within a new world of commerce, business or law necessitates an understanding of such issues in all areas of working life, should not a basic introduction to financial and human 
management as well as personal time management, be part of basic skills to be taught at the undergraduate level as well?

This author is not certain where the appropriate place for such education and training should be, and is not advocating a particular place for this element of training. However, this suggestion is intended to initiate discussion and reaction so that such issues are being considered and that such training is contemplated somewhere, rather than young managers having to learn the hard way through experience and failure.

\section{Client Handler/Manager/Partner}

Clients, at least repeat clients, need the feeling of being "managed" by one lawyer or a group of lawyers within the firm. They would prefer not to have to repeat basic information about their family or business or whatever else is relevant. This is a difficult situation to manage since the needs of both individual and corporate clients can be quite varied at different times, whereas most lawyers are quite specialised in their specific areas of subject matter.

It is therefore necessary to have a level of management above the level of the case worker, and perhaps even above the level of the supervising matter partner. A client partner may have been responsible for introducing the client initially or have been the first point of contact between the client and the firm, or may have grown into this role as a result of the client relationship. Ensuring that the different matters which a firm is handling for one client do not intrude on each other, ensuring that the client's whole picture is known and that the left-hand is aware of what the right-hand is doing are essential elements for managing clients who use the firm for more than one matter even if such use is spread over a number of years.

The knowledge of one lawyer within a practice is imputed to all others by clients, insurers and the court and ensuring the best interests of the client over all matters may be quite a complex task. This role is closest to the traditional picture of the general practice solicitor or "man/woman of affairs" who would advise clients generally, with unfettered common sense about how to conduct their affairs, both personal and business.

The skills involved are, once again, not totally new. Dealing with clients is an essential part of being a lawyer. Considering the whole client was certainly included in the traditional role of a lawyer. But, considering the needs of large corporations, managing the interplay between different groups of lawyers within the firm, working on sets of complex transactions and litigation are a level beyond these more basic tasks and need the input of some theory, gathered from experience, and some training. This is a new role. It would be better to recognise its existence and consider its training needs rather than pretend that nothing in the work of law has changed.

\section{Strategist}

Senior partners, either as heads of department or as head of the firm, now need to be well versed in strategy in preparing and organising their firm or department to cope with change in the law or in financial circumstances. Even individual lawyers working on complex cases need to be strategists in planning their work and their 
approach and ensuring the best ultimate interests of their clients. The latter is not a new task, the former is.

The high level strategy intended to set a firm in a particular economic position in the future needs a sound understanding of the business and commercial elements of the practice of the firm, as well as understanding how to plan a strategy and how to implement change and monitor its effects. this is an area already well studied and taught at business schools throughout the world. However, it is at least arguable that training in such issues should be gradual rather than a sudden immersion in a nine month or a three week course just before becoming senior partner. Assistance in forming and understanding the need for strategy, should be available to a firm at all levels and smaller firms may need this as much, or even more, than larger firms with more varied practice. This is therefore another role which needs both theory and training.

\section{Risk Manager}

The deprofessionalisation of legal practice, turning it into a business, involves understanding the nature of competition and the ability to assess and take business risks. New forms of financing legal practice such as the conditional fee arrangement and the possibility of contingency fees, all necessitate a clear understanding of the risks involved in the firm financing a number of cases at the same time.

Some of the skills involved have a clear precedent in legal work. Ascertaining the likely success of a case has always been an important part of the lawyer's work. But, until now, it has always been possible to lay off the burden of the risks, since it was the client's money that was involved. Lawyers might therefore advise quite strongly that a particular case might not succeed but if a client wished to proceed with the case it would almost certainly go ahead. Now, the position is different. Lawyers will have to organise themselves so that they are absolutely clear of the level of their "exposure" across all cases at all times. This means a very close check on the cost of work in progress and other elements of risk, a clear policy about work intake and strong contractual relations with barristers and experts who are also involved in expenditure on such cases.

This list of legal careers, roles, tasks or skills is not exhaustive and it is not yet organised either in terms of level of seniority or in proper definition. However, it is sufficient to note the evolution of a new set of legal careers and therefore a new set of education and training needs in relation to each of these or the new concepts as a system. Firms which can organise properly their own training will obviously be rewarded, but they are not necessarily the best training vehicles for the future of the profession as a whole; and only the largest firms will be able to organise in this way. If we are to support lawyers working in smaller firms, working for individuals and working for those on legal aid through the Community Legal Service, we will also need preparation for these new careers for all lawyers in order to be able to provide law and to compete in a developing market place. Such educational needs are essential for the vastly changing workplace of law.

Some New Legal Concepts to be Considered as Subject Matter 
In addition to the new forms of legal practice, some new sets of legal concepts are becoming more familiar within a whole range of legal subject categories and may now need to be considered as part of the foundational elements of legal conceptual material to be studied. The development of these concepts arises from a mixture of factors, and not only the development of new forms of practice. Changing law and policy, both through statute and common law and changes of practice and procedure have all equally been involved in crafting these concepts. Some are well-defined and some are rather less well-defined. Some are already part of the teaching system or curriculum within some elements of legal education and some are not. Once again, these intuitive suggestions arise out of observation of legal work in the course of other research. They are offered in order to prime discussion, and not as final comment.

\section{Relative Need}

As the Community Legal Service begins to form and Regional Legal Service Committees make their own decisions about how to allocate the resources of legal aid within a particular region, arguing for the funding of a particular cadre of cases, or arguing for individual cases according to the new Funding Code, will soon become a set of arguments relating to the relative needs of different individuals or types of case. Such issues are already present in the systems of welfare benefit and welfare rights which are both formally and informally processed through a myriad of tribunals, social security decisions, social worker decisions and National Health Service decisions. Such issues will now become far more articulate in a world of relative need and finite resources.

Arguing for the individual needs of particular clients may be insufficient, if it does not also take into account the universe of similar, related or competing needs of others. Lawyers will be forced more into the position of allocators of rights, something which has already happened within legal aid franchising, with the ability to grant green form extensions, or refuse them. As firms are given more internal authority to make such decisions their own need to weigh the ethics, the needs, and any conflict of interest will be heightened. This is a concept which needs more theoretical development, more understanding and more education.

\section{Risk}

Risk is not simply an issue for law firm management but is also an important business concept and will become a legal concept, both to be understood and to be taught. It is related to issues of probability, provability, heuristics and judgement. It is crucial in advising clients on the level of their risk, considering the level of the lawyer's own risk and understanding the nature of relative risks.

Lawyers are brought up to be risk averse. Any possibility for eliminating the element of risk will be embraced and risk is treated as some sort of dreadful disease to be avoided at all cost. But, in fact, there is no such possibility as "zero risk" and there are risks in every situation, every transaction, every strategy, every litigation. Coping with these and utilising them are elements of the world of the stock exchange, commodities exchanges, of trading in currencies and most elements of buying and selling. Risk has therefore now become an area of study of its own and its 
development within the law can easily be predicted. This can no doubt be assisted by the provision of theoretical underpinnings and the education of such ideas.

\section{Right}

The passing of the Human Rights Act 1998 and its coming into force over the next two years will provide a very different view of a legal "right" than has previously existed. Our "constitutionless" legal system without its own written human rights has relied on a set of concepts of "no right" rather than positive rights. One can only say that a citizen of England and Wales would have a "right" to do something which was not prevented by the criminal or civil law or other regulation.

The concept of "right" is therefore a new concept for us. Although it may not be a new concept for law in other jurisdictions, and although there were already other issues relating to the European Convention beginning to come before our courts, this concept will need careful understanding, careful development of theory and careful training of lawyers in the development of a system which may not simply follow where other jurisdictions have gone.

\section{Relationship}

This appears to be a new concept for the law. There are legal subject areas where this has appeared previously such as the "common law" family. However, a new concept appears to be emerging. As a result of the circumstances of the first decision in the House of Lords Pinochet extradition case, the relationship between a Lord of Appeal in Ordinary, Lord Hoffman, with one of the litigating parties - Amnesty International - was queried. It appeared that Lord Hoffman had not declared the fact that he was the chair of a committee raising funds for Amnesty International and that his wife was closely associated with their work.

Some might argue that any judge who was not identified with Amnesty International would not be fit to be a judge. However, this may not be a universally held view. It is clear that such issues will now become of importance in at least considering the panel for any case.

The nature of the relationships between ministers of state such as Mandelson and Robinson in which a minister in one department had, prior to the election of a new government, made a loan to a minister in another department for the purchase of his house and had not declared this relationship or interest, would set up a new type of concept for the law. Similarly the "relationship" between President Clinton and Monica Lewinsky became an importantly loaded set of concepts with a battleground of definitions to fight over. As the major differences in political principles and political parties begin to dissolve into a state of relativism best loved by postmodernism, the concept of "relationship" will become more important to consider within law.

\section{Responsibility}

Coupled with rights in a "communitarian" environment is the concept of "responsibility". Although perhaps not previously considered under this term the 
"duties" or "obligations" at law by one "person" to another have been bundled up in concepts of both contract, tort and criminal law. The concept of "responsibility" takes this further into issues of "status" additionally. This particular concept is not quite the same as liability but is sometimes close to it. It will also take up a clearer definition of the position of professionals in relation to both their clients and to society at large. This is a concept which needs development, theory, understanding and education.

\section{Remedy}

Restitution has sometimes been taught as a specific subject area in some undergraduate programmes. Compared with the United States, however, where remedies have been taught for many years as a separate item we are quite far behind. Viewing a case from the possible remedies which are available is very different from considering the initial facts and placing it within a legal context which seems to apply to those facts. Considering with a client which remedy or remedies they may prefer entails looking through the telescope backwards. What facts might be necessary in order to achieve such remedies? What legal theories are necessary in order to obtain such remedies?

A completely new view of legal material, of litigation and of the purpose of law is available through the remedial eye glass. As a concept we need to work much further on this and teach this area of law from a separate conceptual base.

\section{Quality of Life}

A concept which arose within the psychology of healthcare and has now moved into policy in planning the environment and environmental issues, will also become important within law. If Quality of Life becomes an issue for planning and environmental regulators then it will clearly become a matter for litigation at some point. Quality of life can already be raised in relation to damages for personal injury and other stress and suffering.

As we move into a period where relative needs and values and rights and responsibilities will compete with each other "Quality of Life" will become both a background, and a central, concept for argument in a wealth of different areas. Understanding its cross-disciplinary meaning and applying it within law will similarly be important.

Other concepts which equally need further development might include: public good, utilitarianism and outcome vs. opportunity. They are all concepts in a nascent state within law, but require the illumination of study in their individual sense and context and may subsequently be important concepts in the evolution of basic legal education.

\section{New Legal Subject Classifications}

Finally, attacking the structure of the curriculum itself. Old legal subject boundaries are based on limitations defined by precedential accident and legal work area over generations of development. But the lawyer of the future is a specialist in the particular needs of elements of client work which transcend all legal subject boundaries and centre on the transaction or the litigation itself, or the individual 
client. It may therefore be necessary to reconsider legal subject categorisations in accordance with legal work. Such classification was, in any event, serendipitous. It now needs to be rational.

Such rationalisation does not necessarily imply much development of the law itself, compared with its current position, but the bringing together of headings and subject matter in this way may entail some development, and will in any event provide a more clear, succinct and appropriate classification for the way in which law is considered and practised.

\section{The State}

Sovereign immunity and the Crown, as in Crown Prosecution Service, are certainly well-recognised subject areas. The whole area of administrative law and its constraints on the power of the state could now be joined to these. The laws of Parliament and the growing constitutional law in relation to devolution also belong here. Others may wish to add a number of the sections of the Human Rights Act into this classification, and there will be other subject areas which may fit well here.

Adopting a classification of this nature will more easily allow a multi-disciplinary approach to the consideration of the subject material and its teaching.

\section{The Individual}

Professor Harry Street was perhaps the first to consider the individual in his seminal work Freedom, the Individual and the Law. Some of the areas of individual human rights could certainly now come under this heading. Additionally, issues to do with the beginning and the end of life would appear to come naturally under this heading. Birth registration and "right of life" would certainly be issues of this kind. Euthanasia, living wills, all of probate law and personal tax might all come under this heading.

Others might like to add or subtract or develop this classification, but its clarity and focus are compelling. The reorganisation of subject matter would not be difficult and would probably provide a useful symbiosis of areas currently unnecessarily separated from each other.

\section{The Family}

This is probably the area most close to current areas of legal subject classification. Family law, that is the law of divorce, ancillary relief, violence within marriage, residence and control of children, may all come under this heading. It would be an interesting question to decide whether public law child cases should also come under this heading and whether care orders for children relate also to this - or whether they should more properly come under the heading of the individual in minority. Such a move to the classification of "the individual" would assist the cause of the rights of children and might be a proper move.

Politically also the concept of "the family" and support of the family as shown in the recent government white paper might also be well served by this form of subject 
classification. In any event, both antagonists and protagonists of the family would probably be pleased to see it so clearly and separately classified for distinct attention.

\section{The Corporate Body}

This too is an area with an existing, similar legal subject classification. However, it would be more possible to study the nature of the corporate entity better under this heading than under the title of "company law". Fiscal crime, large scale fraud and charitable body constructions might all come under this form of heading. This would allow the classification and the concept to be open to clearer study.

Modern developments such as the corporate partnership could similarly be studied under this heading and a multi-disciplinary approach would allow an understanding of the corporate body beyond individual jurisdictions and on an international basis. Such international corporations, more powerful in some cases than states, demand interest, careful study and education.

\section{The Trust}

Although this will often be studied by itself, it will most often be considered as a part of that great and varied body of the law known as equity. But if the trust is given its separate legal subject classification it can be seen most easily as another vehicle for the carrying out of transactions, wealth accumulation, capital and income transfer, property holding, all behind a certain level of screen and in a legal construct not too different from that of a corporate body.

The usefulness of the Trust has recently been discovered within the Civil Law world, which does not have such a concept. Appearing to be an anachronism, it retains many benefits above its corporate competitor. As such it may challenge the democracy to which large corporations have become subject. It merits separate, careful academic study and teaching.

\section{The Environment}

Environmental law has already found itself as a separate classification. But the environment may include much more. Rather like "the Quality of Life" it is an all encompassing subject classification which provides a logical, but detailed and multidisciplinary approach to answering many existing and potential problems.

Organising legal subject boundaries around this form of classification releases both those developing the area and those studying it to consider all the elements of law within their natural context.

\section{Capacity}

The needs of those who have difficulty in managing, competing or existing within a modern social framework set up a common strand of theory. The young, the old, the infirm, the mentally ill, the physically ill, the disabled, the unable, the discriminatee, the weak, the powerless, the minority - all may have some call to be included within this classification. Some elements of the law may apply to all and some to only a few. 
Consideration of how the law, social values and society treat incapacity follows clearly from this categorisation.

\section{Conflict}

Conflict of Laws is quite different from Conflict of Interest and the Laws of Conflict, and any attempt to bring all these together would neither be rational nor useful. Here the intention is only to consider Conflict of Interest. This is a growing area of legal importance covering not only the work of lawyers but also the work of other professionals, Ministers and Ministries of State and the proper proprieties of organised and public life in a society based on equality, ethical and democratic principles. Considering Conflict of Interest separately in this way would allow the development of a theoretical consideration of "interest", would progress the development of purity and standards in private and public life and would enable better guidance for the better ethical handling of people and work.

Conflict of Interest has become a major subject area for the model American Bar Association code of ethics, is becoming an area of considerable legal interest in relation to Chinese walls and is a major issue in public life. Once again, it merits separate study.

This list, once again, is not exclusive, nor is it yet well organised or fully defined. The aim of setting it out here is to encourage, even excite, interest; to tease a little and to demand some new approaches in the face of such enormous change.

\section{Conclusion}

Changes within legal practice mirror changes within society. Professions are undergoing major changes in status, organisation, work patterns and work content. The nature of professions and professionalism is changing. Professions are not accorded the special status of untouchable occupational groups whose word is respected and whose competence is undoubted. Sub-professions and sub-specialisms abound. Paraprofessionals feed on the interstices between, and below, specialist areas. Work systems, contexts and contents are changing in order to adapt into a new world of technologically delivered information and industrialised professional service production. The legal profession is no different, although some of the changes are occurring later in law than in medicine, accountancy and architecture. These social changes are mirrored in the development of law itself. Legal practices are fighting hard to keep up, and keep ahead, of these developments. Legal education is far behind in contemplating what changes may be necessary to accommodate what is occurring in the outside world.

The question is whether legal educators should be ahead of these changes, understanding their meaning and preparing both the lawyers of the future and those who study law and what lawyers do for the world in which law will operate. It is essential that we begin the discussion of these issues now so that we can prepare the curriculum, the approach, the subject matter and the skills with which to educate the lawyer of 2010 . 
So far, despite the increasing clarity of the movements portrayed above, legal education at the undergraduate level has remained remarkably unchanged. The growth of options for specialist study at the masters level is an indication of some reaction to the new world of the work of law. The vocational level of training in England, Wales and Scotland has undergone considerable change in the past ten years, but these changes reflect an historical position and do not prepare sufficiently for the present let alone the future.

Not to ask these questions means not even to begin the discussion as to whether legal education should be considering or reflecting these issues. Let that discussion now begin. 